ключевые слова: инновация, инновационная активность персонала организаций, оппортунизм, демотивация, система стимулирования труда персонала организации, система мотивации труда персонала организации

В. Н. Белкин, Н. А. Белкина

\title{
ИННОВАЦИОННАЯ АКТИВНОСТЬ ПЕРСОНААА ОРГАНИЗАЦИИ
}

В статье рассматриваются пути перехода экономики РФ на инновационный путь развития. Особое внимание уделено внутренней социальноэкономической среде организаций, которая, как правило, противодействует развитию инновационной активности персонала. Предложены пути повышения инновационной активности персонала организаций.

В широко развернувшейся дискуссии по проблемам инновационной экономики зачастую звучат упреки в адрес российского бизнеса. Обвиняют его в слабой инновационной активности, невосприимчивости К научно-техническим новинкам, другим новшествам и т. д. В обоснование таких упреков приводится статистика инновационной активности предприятий в развитых странах и РФ, из которой следует, что российский бизнес инновационно менее активен в 5-10 раз. При этом не учитывается объективное положение предприятий в разных странах, та внешняя среда, в которой функционируют предприятия в экономике, находящейся на разных этапах своего развития.

В ведущих западных странах предприятия находятся в такой конкурентной среде, в которой выживание возможно в основном за счет инновационного развития. Совсем иное положение у большинства российских предприятий. Они могут благополучно существовать, не утруждая себя инновациями. Иначе говоря, внешняя среда на российском рынке такова, что внедрение инноваций не является вопросом жизни и смерти предприятий. Именно поэтому они не гоняются и в ближайшем будущем не будут гоняться за инновациями. Из всего этого следует, что важнейшим объективным условием развития инновационной экономики в РФ является становление такой конкуренции, при которой внедрение инноваций является основным средством сохранения предприятий на рынке.

При сравнительном анализе инновационной активности предприятий зачастую не учитывается разная роль государств в западных странах и в РФ. В США, Японии, ряде европейских стран государства проводят политику стимулирования инновационной активности фирм. В России лишь в последнее время зашла речь об этом. Но пока это лишь намерения президента и правительства РФ. Таким образом, главными двигателями инновационной активности предприятий на Западе являются конкуренция и государственная политика стимулирования инноваций. 
Однако это еще не все. Есть третий двигатель - инновационная активность персонала предприятий. Во многих западных фирмах, а также в фирмах Японии уже давно довольно хорошо поставлено управление инновационной активностью персонала. Там не только теоретически установили, но и практически доказали, что самым ценным капиталом является человеческий капитал. И чтобы мобилизовать его, создали системы управления инновационной активностью персонала. Наиболее известной из этих систем является система «Кайдзен», разработанная в японской корпорации «Тойота». Это система «бережливого производства», система мелких улучшений. В последние годы данная система стала распространяться на ряде российских предприятий. Однако в основной своей массе предприятия России не имеют систем управления инновационной активностью персонала. Таким образом, в РФ пока нет ни одного из главных условий перехода к инновационной экономике.

Все большее число специалистов приходят к выводу о необходимости форсированного развития инновационной активности организаций страны, видя в этом главный путь повышения конкурентоспособности российской экономики. Все это нашло отражение в потоке публикаций по проблемам инновационного развития. Их анализ показывает, что в центре внимания исследователей находятся теоретические и методические вопросы, такие как определение понятий «инновация», «инновационная активность», методика оценки инновационной активности предприятий и др.

К сожалению, практически не рассматриваются главные, по нашему мнению, проблемы. Среди них: управление инновационной деятельностью в организациях, стимулирование инновационной активности персонала, экономические и социально-психологические барь- еры на пути инновационного развития страны. Понимая необходимость и всю сложность перевода экономики на инновационные рельсы, Челябинский филиал Института экономики Уральского отделения Российской академии наук на протяжении ряда лет проводил исследования указанных проблем на предприятиях разных отраслей. В центре этих исследований находилась внутренняя среда организаций.

Исследования показали, что в подавляющем большинстве известных нам организаций практически не сложилась система управления инновационной активностью персонала. В лучшем случае стимулируется рационализаторская и изобретательская деятельность работников. Однако ее уровень очень низкий. Даже на крупных предприятиях одно оформленное и внедренное рацпредложение приходится на 100 и более работников в год.

Инновационная активность персонала в решающей степени зависит от системы трудовых отношений, в которую погружены работники. Она может стимулировать инициативу, она же может гасить ее, не давать возможности реализоваться творческому потенциалу работников. Обратимся в связи с этим к результатам социологических опросов, проведенных нами в разных организациях (таблица 1).

Как следует из таблицы, на двух предприятиях число респондентов, считающих, что всякая инициатива наказуема, в 1,5 раза больше, чем число респондентов, считающих, что инициатива поощряется. Лишь на машиностроительном заводе картина обратная, здесь число респондентов, считающих, что всякая инициатива поощряется, в 1,8 раза больше числа респондентов, придерживающихся иной точки зрения. Такая большая разница объясняется тем, что машиностроительный завод десятый год работает по системе «РОСТ», поощряющей всякую инициативу рабочих.

Оценка рабочими инновационной среды в организациях (в \% от числа респондентов)

\begin{tabular}{|c|c|c|c|}
\hline \multirow[b]{2}{*}{ Ответы на вопрос } & \multicolumn{3}{|c|}{ Организация } \\
\hline & $\begin{array}{c}\text { Металлургичес- } \\
\text { кий завод }\end{array}$ & $\begin{array}{c}\text { Машиностроитель- } \\
\text { ный завод }\end{array}$ & $\begin{array}{c}\text { Сельскохозяйственная } \\
\text { организация }\end{array}$ \\
\hline \multicolumn{4}{|c|}{ Скажите пожалуйста, в вашем коллективе какой принцип фактически действует: } \\
\hline всякая инициатива поощряется & 40 & 64 & 36 \\
\hline всякая инициатива наказуема & 60 & 36 & 64 \\
\hline \multicolumn{4}{|c|}{ Если в вашем цехе, участке есть рабочий-рационализатор (новатор), то вы: } \\
\hline отношусь к нему с уважением и поддерживаю его & 35 & 44 & 41 \\
\hline считаю его выскочкой, нескромным человеком & 55 & 36 & 38 \\
\hline мне все равно, рационализатор он или нет & 10 & 11 & 21 \\
\hline
\end{tabular}


Таблица 2

Оценка инновационной среды организаций руководителями первичного (низового) уровня управления (в \% от числа опрошенных)

\begin{tabular}{|c|c|c|c|}
\hline Ответы на вопросы & $\begin{array}{c}\text { Завод резиновотех- } \\
\text { нических изделий }\end{array}$ & $\begin{array}{c}\text { Металлургический } \\
\text { завод }\end{array}$ & $\begin{array}{c}\text { Машиностроительный } \\
\text { завод }\end{array}$ \\
\hline \multicolumn{4}{|c|}{ Скажите, пожалуйста, какой принцип в вашем коллективе фактически действует: } \\
\hline всякая инициатива поощряется & 38 & 34 & 52 \\
\hline всякая инициатива наказуема & 62 & 66 & 48 \\
\hline \multicolumn{4}{|c|}{ Поддерживает ли ваши инициативы вышестоящий руководитель? } \\
\hline поддерживает & 47 & 44 & 44 \\
\hline не поддерживает & 53 & 56 & 56 \\
\hline \multicolumn{4}{|c|}{ Если по вашему предложению внедрились какие-нибудь инновации, то: } \\
\hline вас поощряли материально & 5 & 7 & 8 \\
\hline вас поощряли только морально & 15 & 12 & 23 \\
\hline вас поощряли материально и морально & 11 & 13 & 15 \\
\hline вас никак не поощряли & 54 & 51 & 45 \\
\hline я был не рад, что предложил инновацию & 15 & 17 & 9 \\
\hline
\end{tabular}

* Опросы проведены в 2006-2008 годах. Опрошено от 38 до 82\% от числа руководителей первичного уровня управления.

Весьма симптоматичны результаты опроса рабочих ${ }^{1}$ по поводу их отношения к рабочим-рационализаторам. Лишь около $40 \%$ рабочих относятся к ним уважительно и поддерживают их. Каждый третий считает их выскочками, нескромными людьми, каждый десятый относится к ним равнодушно. Таким образом, исследование показало, что реальная система трудовых отношений организаций неблагоприятна для проявления рабочими инновационной активности.

В тех же предприятиях, в которых используется традиционная система оценки и оплаты труда, основанная на классической или слегка измененной тарифно-окладной системе, нет механизма оперативного поощрения инициативы, инновационной активности работников. Широко распространено уравнительное распределение зарплаты, так что и инициативные и пассивные работники получают ровную зарплату, несмотря на разный трудовой вклад. Что касается премирования, то оно носит исключительно коллективный характер, поощряются целые коллективы структурных подразделений и за коллективные достижения. Один размер премии для всех рабочих-повременщиков, другой для всех руководителей и т. д., т. е. и в системе премирования нет механизма поощрения новаторов.

Вполне понятно, что организации, желая развить инновационную активность персонала, прежде всего возлагают надежды на менеджерский корпус. В связи с этим мы исследовали

\footnotetext{
${ }^{1}$ Опросы проведены в 2006-2008 годах. Опрошено от 12 до $37 \%$ от численности рабочих-повременщиков.
}

отношение менеджеров к инновациям. Прежде всего, нужно было выявить, достаточно ли мотивированы руководители проявлять инновационную активность. Итоги опросов свидетельствуют о том, что в организациях сложилась среда, в которой более половины руководителей первичного уровня управления (мастера, начальники участков, смен и т. п.), считают, что инновационная активность наказуема (табл. 2).

Инновационная активность руководителей подрывается в связи с тем, что их непосредственные руководители не поддерживают их инициативы. На это указывают более половины опрошенных (см. табл. 2). Более половины респондентов имеют негативный опыт инновационной активности. Половина их вообще никак не была поошрена, каждый пятый-шестой руководитель были не рады, что предложили инновацию. Таким образом, руководители первичного уровня управления, по своему положению более других знающие недостатки и проблемы производства, поставлены в такие условия, что далеко не каждый из них заинтересован в инновациях, более половины из них имеют негативный опыт инновационной активности.

Отношение руководителей высшего и среднего уровней управления к инновационной активности нами было выявлено на машиностроительном заводе ${ }^{2}$. Опрос показал, что 14 и $27 \%$ респондентов соответственно никак не поощрялись за инновации, были не рады, что предложили инновации 7 и $8 \%$ руководителей,

\footnotetext{
${ }^{2}$ Опрос проведен в январе 2008 г. Опрошено 87\% руководителей высшего и $75 \%$ среднего уровня управления.
} 
считают, что инициатива наказуема 14 и $15 \%$. Только 64\% руководителей высшего и 55\% среднего уровня управления полагают, что инновационная активность предприятий играет решающую роль в конкурентной борьбе. Каждый пятый руководитель (20\%) считает себя не способным к инновациям и не желает ими заниматься. Из анализа итогов социологических опросов, проведенных на предприятиях трех отраслей, следует, что, во-первых, практически не сложилась система управления инновационной активностью персонала, во-вторых, существующие типичные системы трудовых отношений порождают мощные психологические барьеры в сознании работников на инновационном пути развития экономики, в-третьих, значительная часть менеджеров предприятий недооценивает роль инноваций в конкуренции и не желает заниматься этой деятельностью.

Инновационная активность персонала организаций зависит не только от ее материальной выгодности, денежных поощрений и т. д., но и от той социально-психологической среды, в которой живут и трудятся работники, от корпоративной культуры организации. Иначе говоря, необходима социальная мотивация работников, которая предполагает идентификацию работников с организацией. Если на предприятии широко распространен фирменный патриотизм, большинство работников крепко связаны с ним и не видят для себя иной альтернативы, то это неизбежно положительно отразится на уровне инновационной активности персонала. Если же преобладает отчуждение труда, и завод, фабрика, фирма воспринимаются работниками как чуждый им бизнес, как место, в котором зарабатываются деньги и не более того, как временное место работы, то трудно ожидать в этих условиях активности в инновационной сфере.

В современных условиях происходят весьма существенные изменения в системе стимулов труда. Многие организации, отвергая тарифноокладную систему оценки и оплаты труда, почти непрерывно экспериментируют, меняют соотношение основной и дополнительной зарплаты, условия премирования, набор социальных льгот, вводят разные формы морального поощрения и т. п. При этом многие недостатки тарифно-окладной системы перекочевывают в «новые» системы стимулирования труда.

Ошибки в формировании системы стимулов труда приводят к рассогласованию интересов организации и работников. Так, в тарифно-окладной системе труд рабочих-повременщиков оплачивается в зависимости от рабочего вре- мени. При этом организация ожидает, что нанятый ею работник будет работать интенсивно и инициативно. Однако повременщик скоро усваивает очевидную истину: зарплата не зависит от эффективности его труда, а инициатива, как правило, не поощряется. В этих условиях работник начинает экономить свою рабочую силу, при этом за уменьшающийся труд он получает неизменную зарплату, т. е. организация начинает платить все дороже за каждую единицу затраченного рабочим труда.

В этих условиях возникает и развивается оппортунистическое поведение рабочих-повременщиков, руководителей, служащих и специалистов, т. е. всех тех, у кого нет прямой связи величины оплаты труда с результатами их труда. Появляется стремление отлынивать от работы, нежелание выполнять трудовые функции, если это не замечается руководством, отказ от всякой инициативы, равнодушное отношение к экономическим потерям производства и т. д. Для выявления оппортунистического поведения рабочих-повременщиков нами был приведен социологический опрос в трех организациях (таблица 3 ).

Опрос, в частности, показал следующее. Если в смене кончилась работа, то ждут указаний начальства и ничего не предпринимают от 19 до 47\% опрошенных. Если смена вообще оказалась без всякой работы (пустой), то довольны - от 10 до 19\% респондентов, каждому пятому-третьему рабочему «все равно», т. е. не огорчаются таким положением от 19 до $50 \%$ рабочих. Если рабочие знают причину, по которой может остановиться производство, то ничего не предпринимают от 10 до $23 \%$ респондентов. От 40 до 44\% рабочих не будут проявлять инициативу, если она не оплачивается. От 36 до 64\% респондентов считают инициативу наказуемой. С уважением относятся к рационализаторам меньшинство (от 35 до 44\%) опрошенных, считают их «выскочками» от 36 до 55\% респондентов, относятся к ним равнодушно от 10 до $21 \%$. Как видим, налицо глубоко утвердившееся в сознании рабочих-повременщиков отчуждение труда. При таких обстоятельствах трудно ожидать от них инновационной активности.

Для успешного анализа проблема мотивации труда персонала организаций недостаточно использовать понятия «мотив труда», «мотивация труда», «стимул труда», «стимулирование труда». Назрела необходимость введения в научный оборот нового понятия «демотив труда». Под демотивом труда мы понимаем фактор внутренней и внешней среды организации, негативно 
Показатели оппортунистического поведения рабочих-повременщиков

\begin{tabular}{|c|c|c|c|}
\hline Показатели оппортунистического поведения & $\begin{array}{c}\text { Сельскохозяйственная } \\
\text { организация }\end{array}$ & $\begin{array}{c}\text { Машино- } \\
\text { строительный завод }\end{array}$ & $\begin{array}{c}\text { Металлургичес- } \\
\text { кий завод }\end{array}$ \\
\hline \multicolumn{4}{|c|}{ Скажите, пожалуйста, если за вами нет никакого контроля в смене, то вы: } \\
\hline все равно интенсивно работаю & 90 & 91 & 95 \\
\hline работаю в полсилы & 10 & 6 & 5 \\
\hline делаю вид, что работаю & - & 2 & - \\
\hline постараюсь совсем не работать & - & 1 & - \\
\hline \multicolumn{4}{|l|}{ Если в смене нет или кончилась работа, то вы: } \\
\hline иду к своему руководителю за работой & 20 & 32 & 27 \\
\hline сам нахожу работу & 60 & 49,6 & 26 \\
\hline жду указания начальства & 20 & 19 & 47 \\
\hline \multicolumn{4}{|c|}{ Если смена оказалась «пустой», почти без работы, то вы: } \\
\hline доволен этой сменой & 10 & 19 & 12 \\
\hline огорчен & 70 & 81 & 50 \\
\hline мне все равно & 20 & - & 38 \\
\hline \multicolumn{4}{|c|}{ Если вы знаете причину, по которой работа рабочих-сдельщиков может остановиться и получится простой, то вы: } \\
\hline сообщаю об этом руководителю & 50 & 56 & 60 \\
\hline $\begin{array}{r}\text { принимаю сам меры по устранению этой } \\
\text { причины }\end{array}$ & 40 & 31 & 17 \\
\hline ничего не предпринимаю & 10 & 13 & 23 \\
\hline \multicolumn{4}{|c|}{ Если будет можно опоздать на работу к началу смены или с обеда, то вы: } \\
\hline воспользуюсь такой возможностью & 20 & 16 & 20 \\
\hline откажусь от такой возможности & 80 & 84 & 80 \\
\hline \multicolumn{4}{|c|}{ Если можно не все трудовые обязанности выполнять, не теряя из-за это части зарплаты, то вы: } \\
\hline все равно буду выполнять все обязанности & 90 & 83 & 75 \\
\hline $\begin{array}{r}\text { буду выполнять только те обязанности, } \\
\text { которые контролируются начальством }\end{array}$ & 10 & 17 & 25 \\
\hline \multicolumn{4}{|c|}{ Если за проявленную инициативу в труде вам ничего не заплатят, то вы: } \\
\hline все равно буду проявлять инициативу & 60 & 55,5 & 47 \\
\hline не буду проявлять инициативу & 40 & 34 & 43 \\
\hline пусть проявляют другие & & 10 & 10 \\
\hline \multicolumn{4}{|c|}{ Скажите, пожалуйста, в вашем коллективе какой принцип фактически действует: } \\
\hline всякая инициатива поощряется & 40 & 64 & 36 \\
\hline всякая инициатива наказуема & 60 & 36 & 64 \\
\hline
\end{tabular}

* Опросы проведены в 2005-2008 гг. Опрошено от 12 до 37\% рабочих-повременщиков организации.

влияющий на заинтересованность работников в труде. По сути своей демотив труда есть антипод мотиву труда. Первый понижает мотивацию труда, второй - повышает ее. В условиях реального производства функционирует система демотивов труда. Введение понятия «демотив труда» вполне логично предполагает использование другого родственного понятия - «демотивация труда». Под демотивацией труда мы понимаем процесс снижения уровня мотивации труда персонала под воздействием системы демотивов труда. Демотивация труда выступает антиподом понятия «мотивация труда».

Чтобы в какой-то степени преодолеть указанный односторонний подход к исследованию проблем стимулирования и мотивации труда, нами был проведен опрос руководителей первичного уровня управления на трех предприятиях по проблемам демотивации труда (завод резиновых технических изделий, металлургический завод, завод пластмасс, опрошено более $50 \%$ руководителей).

Анализ результатов опроса показал, что больше всего демотивирует руководителей низкий уровень зарплаты и неопределенность денежного вознаграждения по итогам за месяц (1 и 2 место в рейтинге). Особую ценность для руководителей представляет возможность лично от себя материально поощрять подчиненных рабочих. Отсутствие ее существенно демотиви- 
рует руководителей (3 место). Обращает на себя внимание, что значительно меньше демотивирует руководителей отсутствие возможности от себя лично материально наказывать рабочих (10 место). Из этого следует, что руководители нацелены в большей степени на поощрение, чем на наказание. Однако за этим скрывается также психологическая неготовность многих руководителей первичного уровня управления наказывать рабочих от своего имени.

Демотивирует руководителей первичного уровня управления фактор «не вижу перспективы роста». Он занял 6 место в рейтинге демотивов. Вполне понятно, что не каждый мастер станет директором. Однако руководителям первичного уровня управления должны быть известны пути карьерного роста, примеры такого роста на предприятии, с тем, чтобы ориентировать руководителей на совершенствование личного управления подчиненным коллективом, овладение современными методами управления людьми и т. д. Желательно разрабатывать основные требования к руководителю, стремящемуся к карьерному росту.

Результаты опроса позволили выявить наиболее проблемные стороны производственной жизни руководителей первичного уровня управления на предприятиях. Почти половина опрошенных (47\%) указали на неопределенность их служебных обязанностей, $44 \%$ - на нечеткость постановки задач на смену. К сожалению, не чувствуют себя хозяевами положения на участке $41 \%$ опрошенных. Да это и понятно, у них нет возможности от своего имени наказывать и поощрять рабочих. Демотивируют большинство руководителей (77\%) условия их труда, невозможность общаться с другими руководителями первичного уровня управления (49\%). Существенно влияют на мотивацию руководителей неудачи в работе (63\%).

Итоги опроса высветили основные претензии руководителей первичного уровня управления к их непосредственным руководителям.
Особенно низко оценен уровень их профессиональной компетентности. $82 \%$ опрошенных указывают на то, что некомпетентность непосредственного руководителя существенно демотивирует их. Негативно влияет на руководителей первичного уровня управления также стиль управления их непосредственного начальника (52\%). Почти половина опрошенных (43\%) имеют претензии к начальству в связи с нечеткой постановкой задач на смену. $65 \%$ руководителей указали, что начальство не поддерживает их инициативу, и столько же (65\%) отметили, что начальство не привлекает их к принятию управленческих решений.

Таким образом, исследование показало, что на руководителей, как и в целом на весь персонал организаций действует не только система мотивов, но и демотивов труда. И если первая ориентирует работников на инновационную активность, то вторая, наоборот, ведет к снижению интереса к инновациям. Данный аспект трудовых отношений не изучается на практике, здесь скрывается большой резерв повышения инновационной активности персонала.

Система трудовых отношений, в которую включены работники предприятий, не позволяет полностью использовать их трудовой потенциал. Об этом красноречиво свидетельствуют данные таблицы 4.

Как видно из таблицы, практически каждый третий работник $(34,8 \%)$ твердо знает, что он может работать лучше без всяких дополнительных условий. Более половины (60\%) могут работать лучше при определенных условиях (не могут работать лучше всего лишь $2 \%$ респондентов). Это огромный резерв роста масштабов и эффективности экономики, причем лежащий на поверхности. Для его мобилизации практически не нужны капиталовложения, так как производственные мощности также заняты лишь процентов на 50. Иначе говоря, производительные силы страны используются крайне плохо, в лучшем случае их потенциал мобили-

Таблица 4

Оценка работниками их возможностей работать лучше (\% к числу опрошенных)

\begin{tabular}{|l|c|c|c|c|c|c|}
\hline \multirow{2}{*}{ Варианты ответов } & \multicolumn{7}{|c|}{$\begin{array}{c}\text { Павод металлур- } \\
\text { гического ма- } \\
\text { шиностроения }\end{array}$} & $\begin{array}{c}\text { Текстиль- } \\
\text { ный } \\
\text { комбинат }\end{array}$ & $\begin{array}{c}\text { Авто- } \\
\text { агрегатный } \\
\text { завод }\end{array}$ & $\begin{array}{c}\text { Сельско- } \\
\text { хозяйственная } \\
\text { организация }\end{array}$ & $\begin{array}{c}\text { Приборо- } \\
\text { строительный } \\
\text { завод }\end{array}$ & $\begin{array}{c}\text { Завод элек- } \\
\text { тромашин }\end{array}$ \\
\hline Да & 41 & 26 & 35 & 36 & 36 & 35 \\
\hline Нет & 2 & 4 & 2 & 3 & 1 & 1 \\
\hline $\begin{array}{l}\text { При определенных } \\
\text { условиях }\end{array}$ & 54 & 69 & 58 & 60 & 58 & 61 \\
\hline Затрудняюсь ответить & 3 & 1 & 5 & 1 & 5 & 3 \\
\hline
\end{tabular}


зован на 50\%. Здесь скрываются колоссальные возможности роста экономики, причем такие, которые могут быть мобилизованы самым дешевым способом - за счет улучшения мотивации труда и организации производства.

Необходимость перехода на инновационный путь развития провозглашена руководством РФ как стратегическая задача страны, как главное условие модернизации экономики и всей общественной жизни. Все большее число предприятий разных отраслей ориентируется на инновационную активность. Однако до широкого практического воплощения этой задачи еще далеко. Все вышеизложенное убедительно показывает, что переход к инновационному развитию встретится с большими преградами. Это, с одной стороны, консервативность и антиинновационность сложившихся систем трудовых отношений в организациях, с другой - отсутствие опыта перехода на инновационный путь развития. В связи с изложенным наш филиал сделал попытку разработать систему стимулирования инновационной активности персонала на примере ОАО «Шадринский автоагрегатный завод». С этой целью нами была разработана, а руководством завода внедрена система стимулирования инновационной активности персонала ОАО «ШААЗ», которую мы назвали «Система "Инновация"».

Главной задачей работы была выработка системы оценки и стимулирования, которая бы поставила весь персонал в такое положение, чтобы ему было материально выгодно заниматься инновациями и невыгодно не заниматься ими. Иначе говоря, нужно было разработать двустороннюю систему стимулирования, в которой присутствует и пряник и кнут.

На заводе десятый год действует система «РОСТ», в соответствии с которой любая инициатива каждого работника немедленно поошряется по итогам за истекший месяц. Но далеко не всякая инициатива является инновацией. Например, рабочий проявил инициативу и обучил передовым приемам труда новичка. Приемы эти давно известны в цехе, поэтому их никак нельзя отнести к инновациям. Данная инициатива вознаграждается через коэффициент трудового вклада (КТВ) из фонда зарплаты структурного подразделения. В связи с изложенным перед нами встала практическая задача - определить понятие «инновация».

Теоретический анализ имеющихся в литературе определений позволил нам определить инновацию следующим образом. Инновация это всякое нововведение, повышающее соци- ально-экономическую эффективность производства. Оно может быть в любой сфере деятельности предприятия: в технике, технологии, организации труда, условиях труда, управлении, финансовой деятельности, учете и отчетности и т. д. Оно вовсе не обязательно должно иметь непосредственный экономический эффект, достаточно того, что оно дает социальный эффект (улучшение социально-психологической среды в коллективе, повышение квалификации и знаний и т. д.) Главное - чтобы этого нововведения раньше не было, чтобы оно действительно внедрялось впервые в данном коллективе структурного подразделения. Это нововведение могло быть внедрено в других подразделениях, на других предприятиях, но если оно впервые внедряется в данном конкретном коллективе, то оно признается инновацией. Таким образом, мы разделили инициативы и инновации.

Чтобы пробудить и усилить интерес именно к инновациям, было решено создать специальный инновационный фонд, из которого по итогам за месяц вознаграждаются новаторы. Внедрение инноваций поставлено под жесткий контроль «по вертикали». Как видим, речь пока идет лишь о вознаграждении, о пряниках. Где же кнут?

Учитывая решающую роль руководителей в развитии инновационной активности персонала, было принято решение поставить их в особые, жесткие условия так, чтобы они не только получали поощрение за инновации, но и материально наказывались, если не проявляют инновационную активность. В этих целях была разработана особая система стимулирования инновационной активности руководителей. Основные ее элементы следующие.

В должностные инструкции руководителей и в положения о структурных подразделениях вносятся статьи об обязательной инновационной активности. Таким образом, им вменяется эта обязанность, она обретает юридическую основу. Далее был определен учет и отчетность руководителей о внедренных ими инновациях за каждый истекший месяц. Другим показателем инновационной активности руководителя является среднее число инноваций, приходящееся на одного подчиненного работника. Тем самым на руководителя возлагается ответственность за активизацию инновационной деятельности подчиненного коллектива.

Следующий важнейший элемент рассматриваемой системы - аттестация всех руководителей по инновационной активности по истечении каждого полугодия. Аттестационная 
комиссия, заслушав отчет руководителя, определив его личную активность и активность подчиненного коллектива за полугодие, принимает решение: повысить основную зарплату на следующее полугодие или понизить ее на определенный комиссией процент. Наряду с этим комиссия рекомендует ввести наиболее активных руководителей в резерв на повышение в должности или поставить вопрос о неполном соответствии работника занимаемой должности. Таким образом, каждый руководитель получает материальный мотив: получить вознаграждение за счет инновационного фонда, повысить размер основной зарплаты, попасть в резерв на выдвижение. Наряду с этим руководитель несет материальную ответственность за личную инновационную пассивность и подчиненного коллектива в виде снижения основной зарплаты и возможной утраты должности.

За семь месяцев с момента начала работы по системе «Инновация» были получены следующие результаты. Предложено 1878 инноваций, то есть в среднем по 268 инноваций в месяц. Доля новаторов среди рабочих составила $4 \%$, среди руководителей - 31\%. На поощрение новаторов израсходован $1 \%$ от семимесячного фонда заработной платы. Никогда еще в истории завода не достигались такие выдающиеся результаты.

Характеризуя в целом систему «Инновация», следует указать на следующие ее сильные стороны. Она коренным образом меняет социально-психологическую среду, в которой находятся работники. Предприятие дает четкий сигнал персоналу: инновационная активность всячески поошряется, лучшие новаторы вознаграждаются материально и морально. Героями дня становятся лучшие по инновационной активности структурные подразделения, руководители и рядовые работники. Инновационная активность руководителей открывает им путь к карьерному росту

Одним из важнейших моментов новой системы является то, что она преодолевает уравнительность в распределении зарплаты между творчески активными и пассивными руководителями и рядовыми работниками. Улучшение социально-психологической среды на заводе повышает уровень корпоративной культуры, фирменного патриотизма, понижает уровень оппортунистического поведения персонала. Наряду с этим развивается система экономической и социальной ответственности персонала.

В результате таких преобразований в организации коренным образом меняется отношение к труду и персоналу, к проявлению его творческих способностей. Трудовой потенциал персонала в таких условиях используется наиболее эффективно. Таким образом, система «РОСТ»«Инновация» дает ответы на самые злободневные, острые вопросы производственной жизни ОАО «Шадринский автоагрегатный завод» и других предприятий страны. Несомненно, широкое распространение данной системы поможет быстрее и успешнее перейти предприятиям РФ на инновационный путь развития.

\section{Список литературы}

1. Авсянников Н. М. Инновационный менеджмент. М. : Инфра-М, 2002. 175 с.

2. Белкин В. Н., Белкина Н. А. Барьеры на пути инновационного развития организации // Труды III всероссийского симпозиума по экономической теории. Екатеринбург : Институт экономики УрО РАН, 2008. 54 с.

3. Белкин В. Н., Белкина Н. А. Проблемы инновационной активности персонала организаций // Изменяющаяся Россия. Социально-экономические инновации : материалы XXV международной научно-практической конференции / Урал. соц.-экон. ин-т АТиСО. Челябинск, 2008. Ч. І. с. 87-99.

4. Гунин В. Н. Инновационная активность предприятий. Сущность, содержание, формы. М.: Изд-во ГУУ, 2000.

5. Инновационный менеджмент : учебное пособие для вузов / под ред. С. Д. Ильенковой. М.: Банки и биржи, Юнити, 1997.

6. Кокурин Д. И. Инновационная деятельность. М. : Экзамен, 2001. 237c.

7. Концепция долгосрочного социально-экономического развития Российской Федерации до 2020 г. [Электронный ресурс]. Доступ из справочно-правовой системы КонсультантПлюс.

8. Масааки И. Гемба Кайдзен. Путь к снижению затрат и повышению качества. М.: Альпина Бизнес Букс, 2007. 346 с.

9. Санто Б. Инновация как средство экономического развития : пер. с венг. М.: Прогресс, 1991. 654 с.

10. Фархутдинов И. Р., Трапезников В. А. Инновационное предпринимательство. М.: Волтерс Клувер, 2006. 432 с.

11. Ewans $G$. T. Thinking globalization. Issues for open and distance edication in Austraia and the South Pacific / Nouwens F. (ed.). Crossing Frontiers. Rockhampton : Cantral Queensland University, 1995. p. 312-316. 